\title{
A SEMIÓTICA NA PESQUISA SOBRE IDENTIDADE
}

Lúcia Deborah Araujo (CPII)

Resumo: O presente artigo se inscreve num conjunto de produções acerca do tema da identidade, estudada pelo viés da Semiótica e pretende demonstrar a aplicabilidade desse campo do conhecimento ao desenvolvimento de pesquisa sobre essa temática. Parte-se da compreensão de que os estudos identitários participam de um campo de interesse para o qual convergem variados saberes e disciplinas e defende-se o caráter fundamental da incorporação dessas contribuições para a pesquisa linguística. Discute-se o conjunto de ferramentas e operações que a Semiótica tem a oferecer ao pesquisador, permitindo-Ihe lidar com a materialidade linguística em sua face icônica, de modo a apreender elementos de caráter identitário presentes no texto e com eles construir uma interpretação adequada. Nesse percurso, tomam-se como referenciais teóricos sobre identidade os pensamentos de Castells (2006) e Ventós (1994); sobre os princípios teóricos da Semiótica, tomaram-se os estudos de Peirce (1990) e Eco (2007); para a discussão do desenvolvimento da pesquisa de cunho semiótico, consultamos as operações semióticas de Morentín (2008); acerca da iconicidade verbal, recorremos ao trabalho de Simões $(2009 ; 2013)$. As ilustrações de aplicações concretas dos princípios teóricos aqui abraçados foram recolhidas de pesquisas anteriores sobre o tema da identidade (ARAUJO, 2010; 2017; 2018).

Palavras-chave: Semiótica. Pesquisa. Iconicidade. Identidade. Linguagem.

Abstract: This article is part of a set of productions on the theme of identity. The theme is approached from the perspective of Semiotics and aims to demonstrate the applicability of this field of knowledge to the development of research on this particular matter. First of all, we understand that to accurately study the phenomena that take part in the development of identity it is necessary to go for different disciplines and let some of their aspects merge to feed the linguistic research and make it wider. We briefly discuss the set of tools and operations needed by the semiotician to deal with the linguistic materiality in its iconic aspect, to identify the elements of the text that stand for identity, and accurately understand them. The works of Castells (2006) and Ventós (1994) are taken as theoretical references on identity; the studies of 
Peirce (1990) and Eco (2007) provide the basis for our discussion on Semiotics. The semiotic operations listed by Morentín (2008) and the verbal iconicity, as conceived by Simões $(2009 ; 2013)$ were also guides towards a design of the general research on Semiotics. The illustrations and concrete applications of the theoretical principles embraced here were collected from previous research I developed on the theme of identity (ARAUJO, 2010; 2017; 2018).

Keywords: Semiotics. Research. Iconicity. Identity. Language.

\section{INTRODUÇÃO}

Não há como pensar uma sociedade complexa como a contemporânea sem levar em conta toda a teia de representações em que experiências humanas e as interações sociais estão imersas. Isso implica considerar de perto as linguagens, em geral, e a língua, em particular, especialmente no que se refere a como os processos de representação são construídos, comunicados e perpetuados. Mesmo aqueles pensadores que se interessem por aspectos mais práticos e mais objetivos da sociedade terão de lidar, de alguma forma, com essa dimensão sígnica, porque simplesmente não há mente fora dela.

A vida inteligente se constitui por meio de semioses. A nossa existência individual e também a coletiva decorrem da capacidade humana - ainda que esta não seja exclusivamente humana - de responder aos inputs recebidos do meio e, organizando-os em forma de representações, elaborar 
saberes, desenvolver ações, conhecer, reconhecer e reconhecer-se. Da vivência mais simples ao mais sofisticado conhecimento, o caminho percorrido pela mente para processar esse material é essencialmente o mesmo e está diretamente associado à construção do signo. Entendendo signo como um substituto conceitual para um objeto da esfera da experiência, capaz de estar onde o objeto original não está, e sabendo que ele concretiza e promove a conexão da máquina mental com aquilo que ela pode registrar e identificar, percebe-se a aptidão da mente para o desenvolvimento de um universo de abstrações, o qual traduz e representa o universo vivencial, tornando-o significativo. Seja na percepção quase que estritamente biológica, seja na linguagem não verbal, seja na língua, em toda a sua expressão cultural, encontramos os signos; suas relações formam a trama que, variando em complexidade, será capaz de traduzir o mundo em diferentes dimensões, impulsionando o humano.

Estou convencida de que os processos semióticos perpassam toda sorte de desdobramentos cognitivos humanos e considero que a lente da Semiótica se oferece como instrumento fundamental, mesmo quando esse conhecimento não é, em si, o interesse principal de um 
pensador e/ou pesquisador. Essa é a base das reflexões que farei neste trabalho, como também tem sido a base de minhas convicções nas últimas décadas, sobretudo no tocante ao tema da identidade.

Neste artigo, vamos tratar especificamente da conexão entre o ferramental oferecido pela Semiótica e a pesquisa linguística que versa sobre a identidade, campo de conhecimento para o qual convergem tantos outros saberes. Para demonstrar e ilustrar tal aplicação, faremos remissão a trabalhos anteriores, destacadamente à minha tese de doutoramento em Língua Portuguesa pela UERJ, intitulada Brasil brasileiro: o léxico e a identidade nacional, desenvolvida sob orientação da Profa. Dra. Darcilia Simões, e ao artigo "Suassuna: cavaleiro da vida-nova" (ARAUJO, 2018), resultante de uma comunicação apresentada no VI COLSEMI - Colóquio Internacional de Semiótica, evento produzido e organizado pelo Grupo de Pesquisa Seleprot - Semiótica, leitura e produção de texto.

\section{A PESQUISA SOBRE IDENTIDADE UM CAMPO DE CONVERGÊNCIAS}

A investigação sobre identidade exige do pesquisador abertura a outros campos de conhecimento e até outras ciências, já que se trata de um assunto afeto à dimensão do humano e da cultura. É necessário igualmente demonstrar- 
se disposição para trabalhar num terreno sem estaticidade e, até, sem solidez, afinal a identidade é fluida. Na realidade, os estudos sobre identidade acontecem num campo para o qual convergem vários saberes - é espaço para a História, a Sociologia, a Antropologia, a Psicologia, a Biologia, além da Linguística, para enumerar alguns. Se, por um lado, há riqueza de informações, por outro estabelece-se um grande desafio ao pesquisador no momento de recortar o objeto de pesquisa, a forma de abordá-lo e a literatura de referência. Por isso mesmo, excetuando estudos que tratam a identidade de um ponto de vista muito objetivo, com referências estritas, como o DNA ou as marcas da íris humana, o tema é, em geral, palco de diálogos entre áreas distintas e variadas. E é necessário que seja assim, para que se imprima veracidade e fidedignidade ao trabalho de pesquisa, evitando ao máximo que uma percepção subjetiva do objeto se comunique de modo impressionista à pesquisa, a ponto de comprometer seus resultados.

Quando se pensa sobre identidade, os eixos individual e coletivo emergem - não há identidade individualização, sem se recortar uma figura de um fundo, como também não há identidade sem conexão com um conjunto sociocultural, que, por sua vez, se recorta de outro fundo e, uma vez 
individualizado, vai contrastar com alguns conjuntos e se integrar a outros tantos, assim por diante, sucessivamente. De um intenso jogo de diferenças e semelhanças emergem, portanto, as identidades. Negar ser alguma coisa é também caminhar na direção de afirmar o que se é. Já apontamos em trabalho anterior (CUNHA, 2010) que não se pode implantar a identidade artificialmente - caso se tentasse fazê-lo, o resultado seria uma imposição inconsistente ou ainda de uma apropriação cultural; é possível implantar comportamentos, mas não a identidade. Ela requer tempo e convivência; decorre da percepção e da vivência da alteridade e está sujeita às variações dos componentes do todo social. Identidade é enraizamento.

A identidade, assim constituída, se insinua metonimicamente nas dinâmicas sociais - não é exatamente algo que se apresenta, mas algo que se faz representar, apreensível por indicadores que Ihe assinalam a presença e o perfil. Assim, para que seja possível operar um recorte identitário, é preciso buscar pistas dessa construção mental, pessoal, social, histórica, cultural (veremos adiante como a iconicidade lexical colabora com esse levantamento). A identidade propriamente dita poderá ser, na verdade, apenas inferida; contudo, sua imaterialidade não significa 
que ela não exista. Assim é que, para além da expressão linguística, roupas, comportamentos, adereços, ideologias, criações artísticas, práticas religiosas, entre tantas outras manifestações, podem ganhar status de signos da identidade, desde que a representem.

Por essa amplitude do tema, é essencial que a etapa de levantamento do estado da arte a esse respeito inclua títulos não exclusivamente filiados aos estudos da linguagem, porque só será possível tratar adequadamente o tema da identidade, se forem admitidos ao conjunto de referências alguns dos diferentes estudos que com ele dialogam. $\mathrm{Na}$ língua, espaço em que a marcação cultural e social é forte, não é diferente - as escolhas lexicais e de construções frasais, sejam feitas conscientemente ou não, bem como os significados postos em circulação por meio delas, configuram identidades e colaboram para revelar seus traços:

O povo tem uma identidade, que resulta dos traços manifestados em sua cultura, a qual, por sua vez, se forja e se expressa pela mediação das linguagens, sobretudo, da linguagem verbal. Dessa forma, não há como se debruçar sobre cada um desses itens sem visualizar os outros três e os elos que os unem. (ANTUNES, 2007, p. 93)

A pesquisa linguística interessada em identidade deverá, portanto - e obrigatoriamente -, ser um espaço de diálogo 
com outros saberes. A potência da língua como fator indissociável do processo de construção da identidade é reconhecida, por exemplo, pelo sociólogo Manuel Castells, em seu livro $O$ poder da identidade:

Lançaria a hipótese de que a língua, principalmente uma língua plenamente desenvolvida, constitui um atributo fundamental de autorreconhecimento, bem como de estabelecimento de uma fronteira nacional invisível em moldes menos arbitrários que os da territorialidade, e menos exclusivos que os da etnia. (2006, p. 70)

Para Castells (2006), identidade é conceituada genericamente como "a fonte de significado e experiência de um povo" e, especificamente, em se tratando de atores sociais, como "o processo de construção de significado com base em um atributo cultural, ou ainda um conjunto de atributos culturais interrelacionados, o(s) qual(ais) prevalece $(m)$ sobre outras fontes de significado" (2006, p. 22). Desdobrando o pensamento do sociólogo, podemos afirmar que tudo se assenta, de fato, na significação, no processo semiótico que já mencionamos, cujo estabelecimento se dá naturalmente (ou talvez ousássemos dizer inescapavelmente), a partir do momento em que se é um ator imerso em um caldo cultural, em plena experimentação 
vivencial, a despeito de possuir ou não consciência disso. Esse caldo traz em suspensão ingredientes diversos, de cuja interação emerge a identidade, num processo contínuo de configuração sígnica e de ressignificações.

\section{A MATERIALIDADE LINGUÍSTICA COMO ÍNDICE DE CONSTRUÇÃO SEMIÓTICAS/CULTURAIS}

O contato da consciência individual com a realidade, desde as primeiras ocorrências, que se dão num nível cognitivo básico, às demais experiências, vivenciadas em níveis mais complexos, participa de uma linha sequencial de registro, identificação, conhecimento, representação e reconhecimento, etapas que caracterizam o processamento semiótico. Não há necessariamente uma terminalidade para essa linha, visto que, conforme as experiências ganhem complexidade e também em face dos eventos históricos, acontecem atualizações naturais do processamento semiótico. Gradualmente, vai havendo uma especialização da resultante sígnica, sempre que necessário. Assim, o conjunto de signos construídos e internalizados por cada indivíduo constituirá sempre um acervo provisório, atualizável, passível de descartes e de inclusões. Isso se dá igualmente com relação aos grupos sociais e suas referências - afinal, a cultura é um continuum de processamentos semióticos. 
A língua, como constructo social, também integra esse movimento, permitindo manifestar as semioses já construídas e sendo, ela mesma, objeto de reconstruções. Entendendose a língua como elemento fundamental na constituição de identidades, é natural que ela seja investigada, com o objetivo de se reconhecerem os valores identitários vigentes num dado grupo, numa produção cultural e até numa produção artística, como já afirmamos:

Por não ser a prática semiótica desligada da realidade cultural - ao contrário, ela é interativa e transformadora -, é que a linguagem, igualmente, em todo o seu caráter semiotizante, assume papel agenciador e se afasta de qualquer atuação meramente especular. Ainda que conservadora em sua essência (ou em seu recorte), a linguagem não é apenas um reflexo da realidade cultural; mais que isso, é representação, é expressão que ultrapassa o nível do fenômeno e se inscreve no processamento cognitivo da realidade, chegando a produzir novas realidades. (CUNHA, 2010, p. 88)

Em outros termos, interessa saber como a cultura de modo geral se imbrica com a expressão linguística na representação dos conteúdos imateriais circulantes que constituem marcadores de identidade para diferentes sujeitos. Abordando o vínculo entre língua e cultura, Eco (2007) estabelece que os elementos da experiência seriam 
unidades culturais, representadas por meio de expressões linguísticas. Entende este autor que tais elementos podem constituir uma vivência direta de um sujeito falante ou não, podendo ser referências conceituais a experiências alheias, aceitas como existentes. Para deixar o conceito mais claro, imaginemos a seguinte situação - mesmo que um indivíduo jamais tenha testemunhado um eclipse total do sol, poderá nomear o evento e referir-se a ele, por meio de significados negociados culturalmente. Isso indica que analisar entidades vocabulares e as construções de que participam é procedimento revelador das unidades culturais representadas. Nos dizeres de Eco:

Podemos dizer que as unidades culturais se encontram fisicamente ao nosso alcance. Constituem os signos que a vida social coloca à nossa disposição: imagens que interpretam livros, palavras que traduzem definições e vice-versa. (2007, p. 61)

Justifica-se, assim, a pesquisa em torno da relação entre as unidades culturais e suas representações linguísticas, considerando-as legítimas demonstrações dos valores em (maior ou menor) circulação na sociedade.

Cabe aqui, no entanto, uma ressalva: nos eventos comunicativos em geral, não é incomum que o conteúdo verbal se faça acompanhar de outros elementos, de 
caráter não verbal, que integram a construção sígnica, seja confirmando os significados denotados pela forma linguística, seja imprimindo-Ihes outra face, em construção metafórica, por exemplo, o que confere novas dimensões ao processo global de significação. Portanto, ao mergulhar na dinâmica interativa das palavras com contrapartes na forma de imagens, sonoridades, cores e formas, por exemplo, pode o pesquisador vislumbrar mais conteúdos e desenhar de forma mais apurada o papel representativo dos signos, sobretudo em sua face icônica. Trataremos da iconicidade e de seu papel na pesquisa sobre identidade no próximo tópico, mas, por ora, ainda discutiremos o que chamamos de materialidade linguística.

A linguagem em geral e as línguas especificamente fazemse de um jogo entre o imaterial, conceitual (as ideias postas em circulação, as regras de funcionamento praticadas coletivamente e internalizadas pelos usuários, os modelos mentais e culturais compartilhados em formas cristalizadas, etc.), e seu correspondente material (as palavras e frases realizadas via fonação, a escrita, o registro físico de linguagens como a pictórica e a musical, por exemplo). Os signos constituem-se em ambas as dimensões, no entanto é sobre o correspondente material que o pesquisador pode 
se debruçar; a dimensão imaterial pode ser apenas inferida. Cabe, aqui, uma consideração a respeito do que estamos nomeando como correspondente material - não se trata do significante, isolado de conteúdo, de uma forma apenas; o elemento material do qual o pesquisador pode partir é já um signo pleno - um item lexical, um símbolo num brasão, um conjunto cromático a serviço de uma mensagem, por exemplo. O que denominamos elemento material é, então, signo de um signo imaterial, mental, primário, incomunicável em si, mas representável materialmente. Essa relação básica, descrita por semioticistas como Charles Sanders Peirce (1990) e Umberto Eco (2007), serviu de base para Simões (2009; 2013) defender o trabalho com a superfície textual como porta para uma análise semiótica consistente:

Segundo Simões (2009), mapear o léxico é uma estratégia que opera com marcas sensíveis (sonoras, no texto oral; gráficas, no texto escrito). Trata-se de um processo de orientação da leitura, mormente no que tange à apuração das isotopias plausíveis para interpretação de um texto. Em meio ao material léxico, podemos levantar palavraschave que se repetem na superfície textual e que se vão enlaçando, transformando-se em nós - as âncoras textuais -, que representam as encruzilhadas onde as isotopias (ou recortes temáticos) se encontram e se sobrepõem em um mesmo signo. (SIMÕES; SANTADE, 2013, p. 203-204) 
Vemos, então, que o léxico de um texto ganha especial relevância para o pesquisador da área de linguagens, constituindo trilha inicial para análises, podendo, inclusive, converter-se em caminho pavimentado - passaremos a discutir esse ponto.

\section{A VIA SEMIÓTICA}

Tenho insistido na ideia de que a Semiótica pode prover caminho firme para muitas pesquisas, nas mais diversas áreas. Tal convicção deriva do acompanhamento de um processo de pavimentação persistente e intenso, que vem sendo empreendido por pesquisadores no Brasil e no exterior, e do testemunho ocular de experimentações e aprofundamentos levados a cabo pela Professora Dra. Darcilia Simões, por seus parceiros e por seus orientandos, na UERJ - Universidade do Estado do Rio de Janeiro. Já foi assinalada anteriormente a importância do trabalho com a materialidade textual, mas, não raro, ainda há entre pesquisadores a incerteza sobre se a abordagem semiótica ficaria atravessada por impressionismos e por um elevado nível de subjetividade, o que comprometeria a sua validade no campo científico. Tratemos disso.

O pesquisador Juán Magariños Morentín (2008) apresenta um conjunto de operações semióticas com vistas 
a conferir ao trabalho do semioticista a firmeza necessária. Já nos valemos dessas formulações na tese Brasil brasileiro: o léxico e a identidade nacional, em 2010, e retornaremos a elas aqui, por entendermos que os procedimentos propostos podem tornar a abordagem de fato mais técnica, o que é fundamental, sobretudo quando o objeto de pesquisa são conteúdos culturais em si.

As operações de atribuição, substituição e superação constituiriam, na realidade, testagens a serem feitas quanto ao potencial de significância do signo. A primeira operação consiste na atribuição de valor a uma forma (representâmen, significante); testa-se a combinatória entre esta e outras formas, num dado contexto, resultando daí a percepção do valor que ela assume na sintaxe da semiose. A segunda consiste na substituição em, pelo menos, duas semioses - numa, a forma teria função de semiose substituinte, noutra, de semiose substituída, de modo a estabelecer o valor semântico dos signos. Por fim, a terceira operação corresponde à superação da forma, em que se verificaria o valor pragmático do signo, com suas possibilidades de ampliação dos objetos semióticos gerados por ele e/ou de suas limitações para gerar novos objetos semióticos; seria uma operação focada na interrelação do signo com 
outros objetos semióticos, buscando investigar possíveis esvaziamentos do signo ou ampliações de seu potencial. Morentín (2008) afirma que a observação de apenas uma semiose seria insuficiente para estabelecer o valor semântico acionado pelo signo; somente o cotejo entre semioses de características distintas e a diferenciação entre os valores que uma forma assume como signo e com objeto semiótico seriam capazes de revelar os potenciais do signo.

Ao se obrigar a realizar testagens antes de simplesmente estabelecer que o signo $\mathrm{x}$ representa o objeto y com o valor z, o pesquisador restringe os efeitos da ação de sua subjetividade e de sua própria imersão na cultura e na língua. Em outros termos, ao buscar saber como o signo se relaciona e combina com os demais elementos do contexto; quais outros significados são acionados pelo uso prático deste signo e quais já não têm correspondência com ele; enfim, ao investigar como o signo se comporta de um ponto de vista pragmático, o pesquisador pode realizar o processamento do corpus e de seus itens de modo crítico e mais objetivo, como assinala Simões:

Essa mediação semiótica opera com a lógica que não é a ciência da crença, mas da prova ou da evidência. Portanto, as operações semióticas se configuram como exercícios de raciocínio necessários para 
a apreensão e compreensão da realidade. (2018, p. 6)

No campo da pesquisa sobre identidade, é essencial que haja rigor técnico quanto ao processamento dos dados, como forma de evitar o senso comum e as premissas falsas.

Em frases simples e cotidianas, podemos aplicar operações semióticas sugeridas por Morentín (2006) e reconhecer conteúdos e significados acionados diferentemente por cada item lexical. Vejamos um conjunto de frases, apresentadas em comunicação nossa (ARAUJO, 2017) sobre o tema:

"No Brasil, os poetas são muito criativos". [Apenas se indica o traço positivo da existência de poetas criativos, relacionando-o a um lugar, sem marcar especificamente a pertinência ou a alienação do enunciador.]

"No meu país, os poetas são muito criativos". [Indica-se o traço positivo associado a um lugar ao qual o enunciador se vincula por meio do possessivo; a substituição demonstra que, semanticamente, a identificação entre o enunciador e o traço de criatividade artística fica clara, ainda que possa estar assinalando apenas uma relação de aprovação e não necessariamente de inclusão do enunciador entre os poetas criativos.] 
Fixando os termos iniciais e substituindo o contexto, temos:

"No Brasil, corrupção é mato". [Apenas se indica o traço positivo relacionando-o a um lugar, sem marcas de pertinência ou de alienação.]

"No meu país, corrupção é mato". [De ocorrência menos comum no cotidiano, indicaria identificação entre o enunciador e o traço negativo, embora sem assinalar claramente aprovação ou desaprovação ao conteúdo expresso.]

Tomemos agora uma construção muito comum na fala cotidiana de brasileiros que estão em território nacional:

"Nesse país, corrupção é mato". [O demonstrativo usado - nesse - marca distanciamento do enunciador em relação ao país e, por conseguinte, em relação ao traço corrupção é mato, o que nos autoriza a supor que ele esteja realizando uma avaliação negativa quanto a esse traço, sobretudo pela escolha do substantivo mato. Essa construção é usada com frequência por falantes brasileiros que estão no Brasil, em lugar do uso esperável de neste país, que seria o marcador mais adequado para se expressar a relação de proximidade espacial - ou seja, a escolha do pronome demonstrativo marcador de distanciamento assinala um processo de dissimilação do enunciador quanto à realidade vigente, com consequente distanciamento afetivo.] 
Não discutirei no momento o potencial sígnico de mato (erva daninha; elemento abundante), apenas para nos fixarmos na questão da identidade, mas destaco que o uso metafórico do termo imprime valor crítico ao enunciado e reforça as hipóteses levantadas.

Nesse exercício simples, já é possível verificar como foram trabalhados os signos correspondentes ao objeto semiótico "Brasil, país de origem" (no Brasil, no meu país, nesse país) e as variações de uso e de significação observadas, conforme os contextos fossem positivos (os poetas são muito criativos) ou negativos (corrupção é mato), verificando-se, igualmente, alterações quanto ao grau de adesão do enunciador ao conteúdo manifesto na frase, resultando em maior ou menor identificação entre eles.

\section{SEMIÓTICA E IDENTIDADE}

Quem somos? Essa é mais que uma pergunta filosófica, é um percurso de experimentação na vida, na interação com o outro - que nos ajuda a demarcar nossos limites em função dos dele -; na interação com o meio - que nos ajuda a demarcar nosso território, em múltiplos sentidos do termo -; na interação conosco mesmos - o que nos planta dúvidas e certezas e nos devolve constantemente à pergunta original, tendo para ela variadas respostas. 
Quem somos? Essa pergunta-percurso só é possível porque temos a nosso favor a linguagem em geral e a língua, especificamente. A língua transcende o status de mero código e se veste de historicidade, de ideologias, de temporalidades, conteúdos culturais; é, reconhecidamente, parte essencial de nossa construção identitária (retomemos a fala de Castells (2006), já referida anteriormente, que conceitua a língua como atributo fundamental de autorreconhecimento). Ela nos apresenta e nos representa na sociedade, tanto na tradicional, quanto na sociedade em rede, recortando cada indivíduo do outro e de outras versões de si mesmo. Ela nos pode fazer resistir a intempéries de toda sorte, projetando-nos ao longo do tempo. Nós, entretanto, não somos meros projéteis passivos - somos fator volitivo, ativo, garantidor da sua sobrevivência. A língua nos é e nós a somos, concomitantemente. Tal relação expressa a identidade; a relação do falante com sua língua reflete seu grau de pertencimento a grupos e ao que se convencionou chamar de nação.

A relação vincular dos indivíduos com uma nação passa pelo sentimento de natividade, avança para o de nacionalidade e pode vir a se configurar num sistema de ideias e valores identificado como nacionalismo. $\mathrm{O}$ valor 
semântico de nacionalismo oscila de uma relação leve de identificação ingênua e idealista a uma relação de defesa fundamentalista da nação. Talvez por isso alguns teóricos, como o filósofo Xavier Rubert de Ventós (1994), tenham preferido usar o termo plural, nacionalismos, para dar conta de suas múltiplas expressões. Na realidade, a constituição mesma do nacionalismo, segundo esse pensador, passa por várias etapas, até entrar nas identidades a serem defendidas/ preservadas. A cada etapa, fatores diferentes participam da construção da identidade - fatores primários (etnia, território, religião, língua e similares); fatores gerativos (meios de comunicação e tecnologia, formação de cidades, organização de exércitos, monarquias centralizadas); fatores induzidos (codificação da língua em gramáticas oficiais, crescimentos da máquina burocrática, estabelecimento de um sistema nacional de educação); fatores reativos (defesa das identidades oprimidas e de grupos subjugados, com decorrente busca de identidades alternativas na memória coletiva do povo).

A língua, como vemos, está envolvida em diferentes etapas do desenvolvimento da identidade - na base do processo, no gérmen da identidade; nas etapas intermediárias, com a codificação em gramáticas e a perpetuação da língua em 
instituições educativas e meios de comunicação; e numa etapa de maior maturidade social, em que narrativas não oficiais, mas reconhecidas em seu caráter fundante, são resgatadas e defendidas, em substituição a perfis identitários impostos ou distorcidos, que porventura já não representem adequadamente o coletivo, e também em ações de resistência, em substituição a narrativas cuja construção tenha gerado o apagamento de alguns segmentos culturais. Na língua - e por meio dela, nas narrativas circulantes e nas recuperadas - poderemos encontrar e movimentar as forças que sustentam a identidade. Esquematicamente, temos:

Figura 1 - Esquema da relação entre língua e identidade

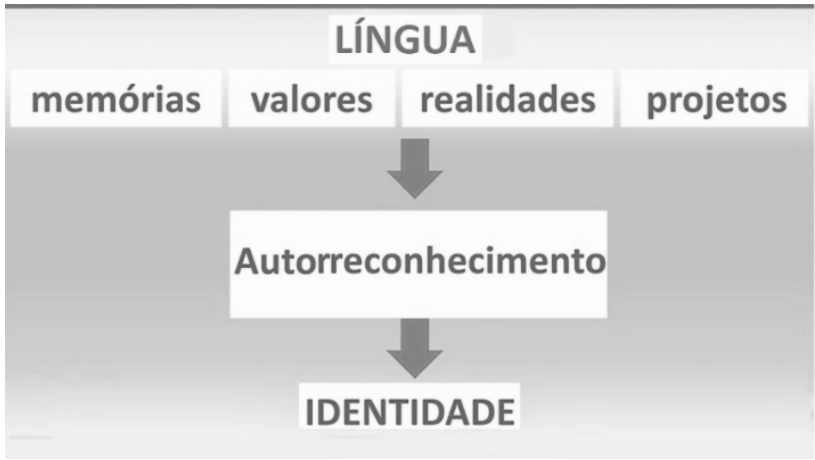

Fonte: Produzido pela autora.

Quando se fala de identidade, é comum evocar-se a filiação de um indivíduo a um grupo ou nação; identifica-se o indivíduo como ser e como parte de um conjunto. Para detectar os valores circulantes relativamente à identidade 
nacional no Brasil e fazê-lo de modo fidedigno, representativo da realidade, empreendemos uma pesquisa com um corpus amplo, composto de 8.000 textos opinativos publicados entre 2005 e 2010 em jornais de grande circulação no país. Processado com ferramentas informacionais da Linguística de Corpus, o corpus revelou um conjunto de itens lexicais sugestivos do perfil identitário vigente, pelo menos entre o público leitor desses grandes jornais.

O trabalho com grandes corpora cumpre a função de oferecer abrangência de dados e ampliar as possibilidades de que as análises sejam representativas da realidade, sobretudo em se tratando de conteúdos culturais de um povo. Os detalhes da pesquisa podem ser consultados em Cunha (2010). Neste espaço, interessa apenas destacar que ficou demonstrada a persistência de representações de determinados valores coletivamente vivenciados e que isso foi detectável por meio da iconicidade verbal, em levantamento quantitativo dos itens lexicais mais frequentes, depois analisados em seus contextos de uso, para determinação de seu potencial semântico e icônico. Traços identitários que o senso comum sugeria serem típicos da conceituação de Brasil e de brasileiro e suas variações foram confirmados, como "jeitinho brasileiro", 
enquanto outros, esperáveis em face dos eventos históricos em curso (a crise do "mensalão" eclodira em 2005), como "corrupção", não se destacaram tanto quanto se supunha que fariam.

A pesquisa sobre a identidade de um povo requer, a nosso ver, amplitude do corpus e rigor científico do pesquisador, para não tratar os dados segundo suas crenças pessoais, nem mesmo segundo o senso comum, sabendo que algumas de suas hipóteses podem ser refutadas.

Consideremos, agora, um perfil de pesquisa mais focal. Sabemos que o processo de construção identitária não se dá somente no âmbito coletivo, mas pode também existir em referência a um indivíduo e até a uma face dele; por exemplo, a face pública de um poeta, em sua condição de artista, com as características que identificam seu estilo, que o recortam de um conjunto de artistas e até de si mesmo, conforme a fase de sua produção (lembremos da fase azul de Picasso, que se recorta do todo de sua obra). Portanto, é possível pesquisar a identidade naquilo que estabelece traços estilísticos, como assinalam as pesquisadoras Simões e Santade (2013), em trabalho de leitura semiótico-funcional sobre poema de Elomar Figueira de Mello. Este poeta, um intelectual de abrangente 
espectro de atuação, tem parte de sua produção feita em língua padrão convencional e parte feita no que ele denomina de vernáculo sertanês, em que construções frasais e grafias ganham aspectos locais e carregam valores culturais. Eis como o poeta justifica sua opção:

Lá bem atrás, eu escolhi o que cantar. [...] $\mathrm{E}$, por conseguinte, cantar as vicissitudes do coração do homem a partir de minhas circunstâncias em minha pátria - o sertão, pelo que entendi que isso só seria possível se o fizesse na língua de cá, por uma questão de inteireza, fidelidade, na variante linguística étnica, ou seja, no dialeto ou vernáculo sertanês. (ELOMAR, apud SIMÕES; SANTADE, 2013, p. 205)

Trata-se, como se percebe, de uma opção linguística assentada sobre uma base identitária, como meio para demarcar e mesmo defender uma posição étnico-cultural. Isso foi muito bem observado pelas pesquisadoras, ao se determinarem a abordar a escrita do poeta como um signo em si, inscrevendo-a em patamar para além da simples grafia com marcas regionais: “Cumpre observar que a grafia em seu texto é signo e deve ser mantida, pois tem por objetivo retratar a fala do homem do sertão, em sua simplicidade" (SIMÕES; SANTADE, 2013, p. 205).

Semelhante abordagem foi feita por nós, em artigo sobre a produção poética de Ariano Suassuna, em que o 
poeta compõe sonetos, muitos resultantes da glosa de motes oferecidos por outros poetas do sertão nordestino no Brasil. Nesses poemas, que, em seu conjunto, ganham aspecto épico e autobiográfico, por registrarem passagens da vida de Suassuna, é possível observar elementos constituintes de sua identidade nordestina, de seu ideário armorial, de sua identidade de artista plástico, de sua identidade musical, de sua identidade de filho de um político assassinado. Tramadas entre si nos versos dos sonetos, tais referências desenham a identidade do poeta, reiterando seu perfil artístico:

Ariano usa de uma linguagem pictórica (natural; Suassuna é um artista plástico que enveredou pela literatura, mas não abandonou o nanquim), que não se limita a descrever subjetivamente o lugar; na verdade, suas palavras fazem cenário e enredo serem praticamente um só elemento. $O$ "aqui" do poeta, o lugar de seu nascimento, no litoral, é identificado sempre por referências que reforçam as tonalidades verde, azul, violeta, preto, apresentadas como deletérias e ameaçadoras, representativas de um lugar de não pertencimento. O "lá" é o local onde se desenrolam sua infância e juventude, referência forte na vida do poeta, idealizado e visto com positividade em sua secura e dureza ocres - esse espaço é apresentado em tonalidades acobreadas, vermelhas, douradas, de temperatura mais elevada. (ARAUJO, 2018, p. 230) 
No artigo em referência, ilustrando a percepção cromática integrante da semiose em um dos textos selecionados, fazemos um levantamento de itens vocabulares que, presentes nessa tapeçaria verbal, marcam o litoral, local de dolorosas experiências para o poeta, onde seu pai foi assassinado, por meio de vocábulos e expressões como "Mangue, a Rosa da infecção (característica putrefata), o Lodo que mancha o Gato Pardo", no espectro do verde e da escuridão; o sertão, espaço onde o eu do poema foi feliz, é marcado pela presença dos elementos de espectro mais vibrante e luminoso: "o pelo de cobre do Alazão, o Bilro de ouro, a lã vermelha, o fogo e a limalha, o Sol e o Sangue" (ARAUJO, 2018, p. 230). Note-se que o cenário cromático é evocado a partir de itens lexicais selecionados cuidadosamente pelo poeta.

De modo semelhante, signos da cultura armorial surgem na poética de Suassuna, compondo toda uma representação regional, histórica e identitária, configurada em referências à Moça Caetana, representação de sedução e terror, vida e morte; à Onça; a animais comumente presentes nos brasões de família; ao Rei, para citar alguns. Para trabalhar com esses elementos, buscamos apurar seu potencial icônico, levando em conta seu poder de sinalizar processos mentais: 
A iconicidade, por ser característica destacada de um tipo de signo que se volta para a qualidade atribuída a um objeto - um qualissigno -, sinaliza os processos mentais realizados para significar/ressignificar 0 mundo circundante, com todas as suas mutações, e traduz um conjunto de elementos que tão-somente se ensaiam nos discursos sociais, venham eles ou não a constituir signos de maior estabilidade e densidade [...]. (SIMÕES; ARAUJO; REIS, 2017, p. 172)

O entendimento de que as referências nos poemas de Ariano desenham sua identidade está alinhado com a noção de que

a iconicidade é uma qualidade de natureza plástico-imagética que pode orientar o olhar do leitor para uma tomada do texto como um desenho constituído por um traçado complexo em que podem misturarse às letras das palavras e enunciados, formas, cores, posições, figuras etc.; do diálogo entre essa variedade de signos resulta a compreensão da mensagem. (SIMÕES, 2009, p. 101)

Com base nessa convicção, Simões (2009) propõe que se mapeie o texto em busca de trilhas icônicas configuradas em âncoras lexicais reveladoras de isotopias, que, por sua vez, fornecerão os alicerces para a construção da leitura interpretativa de orientação semiótica. 


\section{CONSIDERAÇÕES FINAIS}

Compreendemos que o trânsito da iconicidade se dá no emocional, no perceptual, precedendo a ação propriamente dita, que se inscreve na ordem dos índices, e prenunciando a construção de novos contratos semióticos, que se inscrevem na ordem dos símbolos - por isso ela tem poder de revelar conteúdos não verbalizados, mas que subjazem aos processos mentais em curso na criação textual e assumem função orientadora em sua leitura. Logo, podemos entender que a iconicidade guarda estreita relação com a identidade:

O ícone é, portanto, capaz de revelar o que ainda não se ousou dizer, propriamente, já que dialoga com uma dimensão qualitativa da percepção. Por isso, a se desejar capturar os vetores ideológicos de uma sociedade, sobretudo aqueles que atuam no redirecionamento do estado-de-coisas, devese priorizar o estudo dos signos icônicos. (CUNHA, 2010, p. 89)

Assim, a pesquisa sobre identidade encontra no estudo da iconicidade verbal, abordada sobretudo em sua face lexical, ferramenta de grande valor. Por meio do potencial icônico, é possível ter acesso a conteúdos que não surgem declarados, que não se expõem na superfície textual, mas que subjazem aos ditos do texto, estruturando valores e 
demarcando identidades. A pesquisa sobre identidade pode e deve ser feita pela chave da Semiótica. Com vistas a dar conta dos imbricamentos inerentes aos processos culturais envolvidos, deve ser alimentada pelo diálogo com saberes que se avizinham do tema.

Muitas pesquisas podem hoje ser levadas a cabo, porque houve trabalhos pioneiros, quando ainda havia grande incerteza. Uma vez empreendidos, esses estudos iniciais contribuíram para o aprimoramento do ferramental teórico à disposição dos pesquisadores. O mapeamento do texto para fins de apuração do potencial icônico de seus elementos, por meio da identificação de âncoras textuais; o emprego de operações semióticas; a compreensão do fenômeno semiótico em sua profunda relação com interfaces culturais, tudo isso tem reservado para os estudos sobre identidade por via da Semiótica um espaço para se exercerem com metodologia e controle.

A identidade é campo fértil já arado, mas ainda ávido de semeaduras.

\section{REFERÊNCIAS}

ANTUNES, Irandé. A língua e a identidade cultural de um povo. In: VALENTE, André (Org.). Língua portuguesa e identidade: marcas culturais. Rio de Janeiro: Caetés, 2007. p. 93-102. 
ARAUJO, Lúcia Deborah. Suassuna: cavaleiro da vida nova. In: SIMÕES, Darcilia (Org.). Semiótica, pesquisa e ensino. Rio de Janeiro: Dialogarts, 2018. p. 122-144.

ARAUJO, Lúcia Deborah. Nas raízes aladas da identidade. Comunicação apresentada no projeto Rodas de Conversas: Língua portuguesa, identidade e resistência, no Instituto de Letras da Uerj, em 13 de fevereiro de 2017. Promoção do Departamento de Língua Portuguesa, Literatura de Portuguesa e Filologia; Coordenação da Profa. Dra. Darcilia Simões. Disponível em: http://luciadeborah.blogspot.com.br. Acesso em 22 jan. 2021.

CASTELLS, Manuel. O poder da identidade - A era da informação: economia, sociedade e cultura. Vol. 2. Tradução de Klauss Brandini Gerhardt. São Paulo: Paz e Terra, 2006.

CUNHA, Lucia Deborah Araujo de Salles. Brasil brasileiro: o léxico e a identidade nacional. Orientadora: Darcilia Marindir Pinto Simões. 2010. 173f. Tese (Doutorado em Letras) - Instituto de Letras, Universidade do Estado do Rio de Janeiro. Rio de Janeiro. 2010.

ECO, Umberto. Tratado geral de semiótica. Tradução de Antonio P. Danesi e Gilson Cesar C. de Souza. São Paulo: Perspectiva, 2007.

MORENTíN, Juan Magariños de. Conceito e Método da Semiótica. Tradução de Darcilia Simões. In: SIMÕES, Darcilia (Org.). Mundos Semióticos Possíveis. Rio de Janeiro: Dialogarts, 2008.

PEIRCE, Charles Sanders. Semiótica - The Collected Papers of Charles Sanders Peirce. 2. ed. Tradução de J. Teixeira Coelho Neto. São Paulo: Perspectiva, 1990.

SIMÕES, Darcilia. Iconicidade Verbal: Teoria e prática. Rio de Janeiro: Dialogarts. 2009. Disponível em: www.dialogarts.uerj.br. Acesso em 22 jan. 2021.

SIMÕES, Darcilia(Org.). Semiótica, pesquisa e ensino. Rio de Janeiro: Dialogarts, 2018.

SIMÕES, Darcilia; ARAUJO, Lúcia Deborah; REIS, Rosane. Iconicidade verbal: aplicações no ensino de línguas. In: OSORIO, Paulo (Coord.); 
GROSSO, Maria (Dir.). Teorias e usos linguísticos: aplicações ao português língua não materna. Lisboa: Lidel, 2017.

SIMÕES, Darcilia; SANTADE \& Ma. Suzett B. Retirada - cantando a vida no sertão. Caderno Seminal Digital, Rio de Janeiro, n. 19, v. 19, 2013, p. 194-214. Disponível em: https://www.e-publicacoes.uerj.br/index.php/ cadernoseminal/article/view/12068/9449. Acesso em 22 jan. 2021.

VENTÓS, Xavier Rubert de. Nacionalismos - el laberinto de la identidad. Spanish Edition. Espasa Hoy, 1994.

Lúcia Deborah Araujo é doutora em Língua Portuguesa, sob orientação da Profa. Dra. Darcilia Simões, pela UERJ, de onde já foi Professora Adjunta entre 2012 e 2018. Atua hoje no Colégio Pedro II, em Dedicação Exclusiva, desenvolvendo suas atividades no Ensino Médio e no Programa de Pós-graduação, como professora da EaD e Supervisora do Programa de Residência Docente no Campus Tijuca II, no Departamento de Português e Literaturas de Língua Portuguesa. Organizou, com F. Coelho e J. Silva, o volume Literatura, leitura e gêneros textuais - contribuições do/ao ensino de língua portuguesa, editado pela Dialogarts. Em parceria com A. Conforte, é autora dos livros Circuito de Aprendizagem - Língua Portuguesa Mineiridade (vol.1) e Meu Brasil Brasileiro (vol.2), editados pela Fundação Roberto Marinho. Está concluindo pós-doutorado em Língua Portuguesa na UERJ, sob supervisão do Prof. Dr. José Carlos de Azeredo, com pesquisa na área de Semântica, Identidade e Discursos do Feminino. Coordenou junto ao CETREINA-UERJ o Projeto Sintaxe à Vontade, dedicado à investigação do ensino da sintaxe do português. Lattes: https://wwws.cnpq.br/cvlattesweb/PKG_MENU.menu?f_cod=8 DFFAEAF367D4F2AFECFEB2FBB774231\# Email: luciadeborah@gmail.com 